INDO GLOBAL JOURNAL OF

\title{
Characterization and Antimicrobial Activity of Actinomycete Isolate RK-324 from Limestone Rock
}

\author{
Nidhi Srivastava, A. Ibeyaima, Indira P. Sarethy * \\ Department of Biotechnology, Jaypee Institute of Information Technology, A-10, Sector-62, Noida - 201307, India \\ Address for Correspondance: Indira P. Sarethy, indirap.sarethy@jiit.ac.in
}

Keywords

Limestone Rock; Actinomycete; Antimicrobial; Natural Products.

\begin{abstract}
It is imperative to discover novel antimicrobial compounds from bacteria/ fungi because of increasing multidrug resistant pathogens, the proven ability of natural products as skeletons for antimicrobial drugs and the lack of synthetic alternatives. It is however very difficult to find such compounds from known microorganisms due to redundancy. So, there is need to isolate, characterize and screen isolates from under or unexplored habitats. Limestone rocks are habitats with excess calcium carbonate content and with highly basic $\mathrm{pH}$. These have been much less studied for microbial diversity. During a screening programme for microorganisms, actinomycete were isolated from limestone rock (location Maldeota, Uttarakhand). A promising isolate, RK-324, was characterized for antimicrobial activity. This isolate showed antimicrobial activity against Bacillus subtilis [MTCC-121], Staphylococcus aureus [MTCC-435], Escherichia coli [MTCC1679], Saccharomyces cereviseae [MTCC151] and Pseudomonas fluorescens [MTCC-1679]. The aqueous and organic solvent extracts were investigated for antimicrobial activity. Maximum antimicrobial activity was observed in ethyl acetate extract. The isolate also possessed casein, starch and cellulose hydrolysing activities, apart from being catalase positive, producing siderophore and having ability to solubilise phosphate. Antimicrobial product purification and characterization will be discussed..(C) 2016 iGlobal Research and Publishing Foundation. All rights reserved.
\end{abstract}

Conference Proceedings: International Conference on Advances in Plant and Microbial Biotechnology (PMB2017); JIIT, Noida: February 02-04, 2017

Indo Global Journal of Pharmaceutical Sciences( ISSN 22491023 ; CODEN- IGJPAI; NLM ID: 101610675) indexed and abstracted in EMBASE(Elsevier), SCIRUS(Elsevier),CABI, CAB Abstracts, Chemical Abstract Services(CAS), American Chemical Society(ACS), Index Copernicus, EBSCO, DOAJ, Google Scholar and many more. For further details, visit http://iglobaljournal.com 